Saudi Journal of Medicine

Abbreviated Key Title: Saudi J Med ISSN 2518-3389 (Print) |ISSN 2518-3397 (Online) Scholars Middle East Publishers, Dubai, United Arab Emirates

Journal homepage: https://saudijournals.com/sjm

Original Research Article

\title{
Predictive Value of the C-Reactive Protein to Albumin Ratio in Patients with Traumatic Brain Injury
}

\author{
Serkan Dogan ${ }^{1}$, Ozgur Sogut ${ }^{2 *}$, Melis Dörter ${ }^{1}$, Özgür Deniz Sadioğlu ${ }^{2}$, Utku Murat Kalafat ${ }^{1}$, Dilay Satılmış ${ }^{3}$ \\ ${ }^{1}$ University of Health Sciences, Kanuni Sultan Süleyman High Speciality Educational and Research Hospital, Department of Emergency Medicine, \\ Istanbul, Turkey \\ ${ }^{2}$ University of Health Sciences, Haseki High Speciality Educational and Research Hospital, Department of Emergency Medicine, Istanbul, Turkey \\ ${ }^{3}$ University of Health Sciences, Sultan 2. Abdulhamid Han Training and Research Hospital, Department of Emergency Medicine, Istanbul, Turkey
}

DOI: $10.36348 / \mathrm{sjm} .2020 . \mathrm{v} 05 \mathrm{i} 02.004$

| Received: 30.01 .2020 | Accepted: 06.02.2020 | Published: 09.02.2020

*Corresponding author: Ozgur Sogut

\section{Abstract}

Background: We evaluated the predictive power of the C-reactive protein (CRP)/albumin ratio for intraparenchymal injury and the severity thereof in patients with head trauma. Methods: One hundred and seventy-five consecutive adult patients with head trauma admitted to our tertiary care emergency department from January to December 2017 were included in this retrospective study. The patients were divided into the following two groups: those without (group 1) and with (group 2) pathological findings related to head trauma on cranial computed tomography (CCT). The patients were also divided into two subgroups based on the presence or absence of traumatic parenchymal lesions (e.g., brain swelling, cerebral contusion, intracerebral hematoma, and pneumocephalus, defined as traumatic brain injury (TBI). Observations and Results: CCT revealed that 124 (70.8\%) patients had pathological findings (CCT+), of which skull fracture was the most common $(n=50$ patients). Compared to head trauma patients without pathological lesions on CCT (group 2), the mean serum CRP/albumin ratio was significantly elevated in patients with pathological lesions (group 1). Of the 175 patients, 104 (59.4\%) exhibited trauma-related parenchymal lesions on CCT. Compared to head trauma patients without TBI, the mean serum CRP/albumin ratio was markedly elevated in patients with TBI. Conclusions: An increase in the serum CRP/albumin ratio in patients with TBI enables discrimination of those with and without pathological lesions on CCT. The CRP/albumin ratio might be predictive of trauma-related parenchymal lesions in patients with head trauma.

Keywords: Head trauma, C-reactive protein to albumin ratio, cranial computed tomography, traumatic brain injury.

Copyright @ 2020: This is an open-access article distributed under the terms of the Creative Commons Attribution license which permits unrestricted use, distribution, and reproduction in any medium for non-commercial use (NonCommercial, or CC-BY-NC) provided the original author and source are credited.

\section{INTRODUCTION}

Head trauma is one of the most important causes of mortality and morbidity in developed countries, particularly in those aged $>45$ years. It accounts for approximately $20 \%$ of patients admitted to hospital emergency departments (EDs) [1]. The most common causes of head trauma include traffic accidents, falls, and blows to the head. Approximately $50 \%$ of all trauma-associated deaths annually result from head injury. Of surviving head trauma patients, $40-50 \%$ recover without sequelae [2].

Traumatic brain injury (TBI) is classified based on the state of consciousness, irrespective of the underlying injury. Therefore, the underlying pathophysiology can be dramatically different in patients with TBI of similar severity [1, 3]. TBI is classified based on the Glasgow Coma Scale (GCS), which categorizes the degree of injury as severe (GCS score 3-8), moderate (GCS score 9-13), or mild (GCS score 14-15) [3]. TBI has high morbidity and negatively impacts the quality of life of patients [4]. A recent study reported that the incidence of TBI-related ED visits, hospitalizations, and deaths occurred in the United States was 2.8 million in 2013. This consisted of approximately 2.5 million TBI-related ED visits, approximately 282,000 TBI-related hospitalizations, and approximately 56,000 TBI-related deaths [5].

C-reactive protein (CRP) and albumin are used as serum markers of inflammation to predict mortality in critically ill patients [6]. The prognostic power of CRP and albumin is due to their ability to reflect inflammation in the acute phase in critical situations. The level of CRP, an acute-phase protein, is markedly elevated in the presence of infection or inflammation [7]. The relationship between the serum CRP/albumin level and the prognosis of inflammation-mediated diseases such as sepsis, cancer, acute pancreatitis, ulcerative colitis, hepatitis $\mathrm{B}$, and coronary artery disease, has been investigated [8-14], However, no 
clinical study has focused on the relationship of the serum CRP/albumin ratio with the clinical outcomes and severity of head trauma.

We evaluated the predictive power of the CRP/albumin ratio for intracranial injury and the severity thereof in patients with head trauma. The hypothesis was that the CRP/albumin ratio would be of prognostic value for such patients.

\section{MATERIALS AND METHODS}

This retrospective study involved 175 adult head-trauma patients admitted to the emergency department (ED) from January to December 2017. The Glasgow Coma Scale (GCS) score, Revised Trauma Score (RTS), and CRP/albumin ratio of the patients were evaluated at the time of admission. Only patients for whom preprocedural serum albumin and CRP levels were available were evaluated for inclusion. Of 2206 patients with head trauma admitted to the ED, 175 were eligible for analysis.

This retrospective cross-sectional study was conducted in accordance with the 1989 Declaration of Helsinki and was approved by the Ethics Committee of Kanuni Sultan Suleyman Research and Training Hospital (Institutional Review Board no. KAEK/2O1 8.6.2 1; July 06, 2018).

The Glasgow Coma Scale (GCS) score, Revised Trauma Score (RTS), mechanisms of head trauma, CRP/albumin ratio, and cranial computed tomography (CCT) findings of the patients were recorded at the time of admission. The patients were divided into the following two groups: those without (group 1) and with (group 2) pathological findings related to head trauma (e.g., skull fracture, brain swelling, cerebral contusion, intracerebral hematoma, and pneumocephalus) on CCT. The patients were also divided into two subgroups based on the presence or absence of traumatic parenchymal lesions (e.g., brain swelling, cerebral contusion, intracerebral hematoma, and pneumocephalus), defined as traumatic brain injury (TBI). Quantitative data are presented as means \pm standard deviation (SD) or medians (interquartile range). Categorical variables are presented as numbers and percentages. To compare between two groups numerical data that were not normally distributed as determined by Kolmogorov-Smirnov Z-test, the MannWhitney U-test was used. Spearman's rank correlation coefficient (rho) was used to evaluate the correlations between the CRP/albumin ratio and non-normally distributed nonparametric data (GCS and RTS scores).

\section{INCLUSION CRITERIA}

The inclusion criteria were adult patients $(\geq 18$ years) with isolated head trauma. During the first $24 \mathrm{~h}$ after ED admission, CCT was performed in patients with a GCS score of 14 or 15 with at least one of the New Orleans criteria (age $\geq 60$ years, headache, vomiting, alcohol or drug intoxication, short-term memory deficit, signs of trauma above the clavicle, and seizures) or a GCS score of < 14 [15].

\section{EXCLUSION CRITERIA}

The exclusion criteria were less than 18 years of age; injury to the extremities, abdomen, or thorax; history of drug use within the last 1 week (e.g., anti-inflammatories, antibiotics, statins) that could affect the CRP level; and accompanying systemic infection, chronic illness, or malignancy.

\section{RESULTS}

Of the 175 patients analyzed, $145(82.9 \%)$ were males and $30(17.1 \%)$ were females. The mean \pm standard deviation (SD) age of the patients was $46.29 \pm$ 19.63 years (range 18-87 years). The mechanisms of injury of the patients with head trauma were falling from a height $(58.9 \% ; \mathrm{n}=103)$, assaults $(15.4 \%$; $\mathrm{n}=27)$, motor vehicle-pedestrian accidents $(12 \%$; $\mathrm{n}=21)$, motor vehicle accidents $(9.7 \% ; \mathrm{n}=17)$, and motorcycle accidents $(4 \% ; n=7)$. Table-1 shows the demographic characteristics of the patients.

The GCS score ranged from 3 to 15 , with a mean \pm SD of $13.30 \pm 3.60$ and the RTS ranged from 3.1 to 7.8 with a mean \pm SD of $7.40 \pm 1.07$. The CRP/albumin ratio ranged from 0.02 to 41.5 with a mean \pm SD of $2.39 \pm 5.37$. The GCS score and the RTS were not significantly correlated with the CRP/albumin ratio (rho $=-0.097, \mathrm{p}=0.201$ and rho $=-0.020$, $\mathrm{p}=0.797$, respectively).

CCT revealed that $124(70.8 \%)$ patients had pathological findings $(\mathrm{CCT}+)$, including linear fractures, collapse fractures, or TBI; 51 (29.2\%) patients had normal findings. Skull fracture was the most common finding in 50 patients. Compared to head trauma patients without pathological lesions on CCT (group 2), the mean serum CRP/albumin ratio was significantly elevated in those with pathological lesions (group 1) $(2.92 \pm 6.20$ vs. $1.10 \pm 1.86 ; \mathrm{p}=0.039$; Figure-1). Of the 175 patients, 104 (59.4\%) exhibited trauma-relevant parenchymal lesions, including brain swelling, cerebral contusion, intracerebral hematoma, and pneumocephalus, on CCT. Compared to head trauma patients without TBI, the mean serum CRP/albumin ratio was markedly elevated in those with TBI $(3.40 \pm 6.67$ vs. $0.89 \pm 1.61 ; \mathrm{p}=0.001$; Figure-2). The mean serum CRP/albumin ratio was higher in hospitalized than in discharged patients $(3.16 \pm 6.45$ and $1.00 \pm 1.73$, respectively; $p=0.006)$. 
Table-1: Demographic details of patients with head trauma $(n=175)$

\begin{tabular}{|c|c|c|}
\hline Descriptive Properties & & n (\%) \\
\hline \multirow[t]{2}{*}{ Age (year) } & Min-Max (Median) & $18-87(43)$ \\
\hline & Mean \pm SD & $46.29 \pm 19.63$ \\
\hline \multirow[t]{2}{*}{ Gender } & Male & $145(82.9)$ \\
\hline & Female & $30(17.1)$ \\
\hline \multirow[t]{2}{*}{ Systolic Blood Pressure (mmHg) } & Min-Max (Median) & $80-220(145)$ \\
\hline & Mean \pm SD & $150.12 \pm 27.22$ \\
\hline \multirow[t]{2}{*}{ Diastolic Blood Pressure (mmHg) } & Min-Max (Median) & $45-140(82)$ \\
\hline & Mean \pm SD & $84.79 \pm 16.46$ \\
\hline \multirow[t]{2}{*}{ Heart rate } & Min-Max (Median) & $57-150(82)$ \\
\hline & Mean \pm SD & $83.66 \pm 11.35$ \\
\hline \multirow[t]{2}{*}{ Respiratory rate } & Min-Max (Median) & $15-30(21)$ \\
\hline & Mean \pm SD & $21.94 \pm 2.84$ \\
\hline \multirow[t]{2}{*}{ Oxygen saturation $(\%)$} & Min-Max (Median) & $90-100(98)$ \\
\hline & Mean \pm SD & $97.95 \pm 2.32$ \\
\hline \multirow[t]{2}{*}{ Pulse pressure (mmHg) } & Min-Max (Median) & $20-125(63)$ \\
\hline & Mean \pm SD & $65.31 \pm 21,20$ \\
\hline \multirow{5}{*}{ Mechanism of injury } & Falling from a height & $103(58.9)$ \\
\hline & Assaults & $27(15.4)$ \\
\hline & Motor vehicle-pedestrian accidents & $21(12)$ \\
\hline & motor vehicle accidents & $17(9.7)$ \\
\hline & motorcycle accidents & $7(4)$ \\
\hline Clinical outcome & $\begin{array}{l}\text { Excitus } \\
\text { Discharged } \\
\text { Hospitalized }\end{array}$ & $\begin{array}{l}2(1.1) \\
60(34.3) \\
113(64.6)\end{array}$ \\
\hline
\end{tabular}

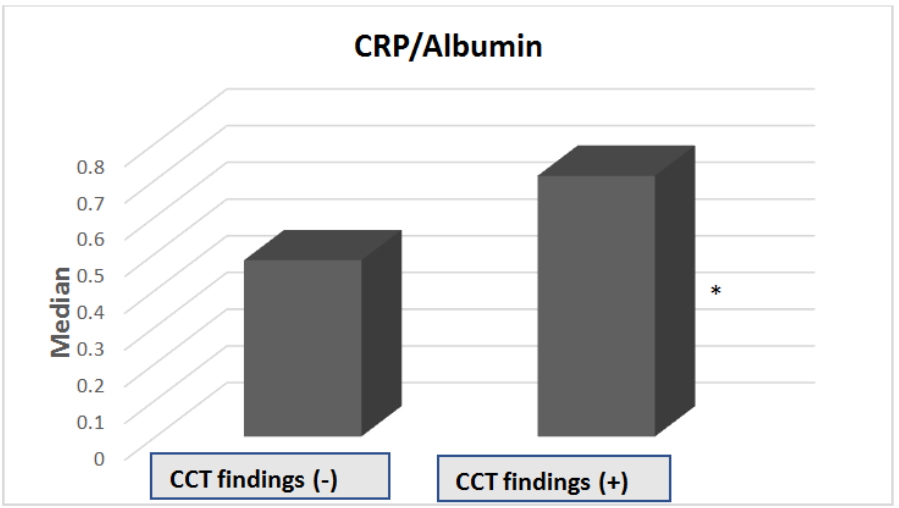

Fig-1: Comparison of the mean serum CRP/albumin levels in patients with pathological lesions and without pathological lesions on CCT

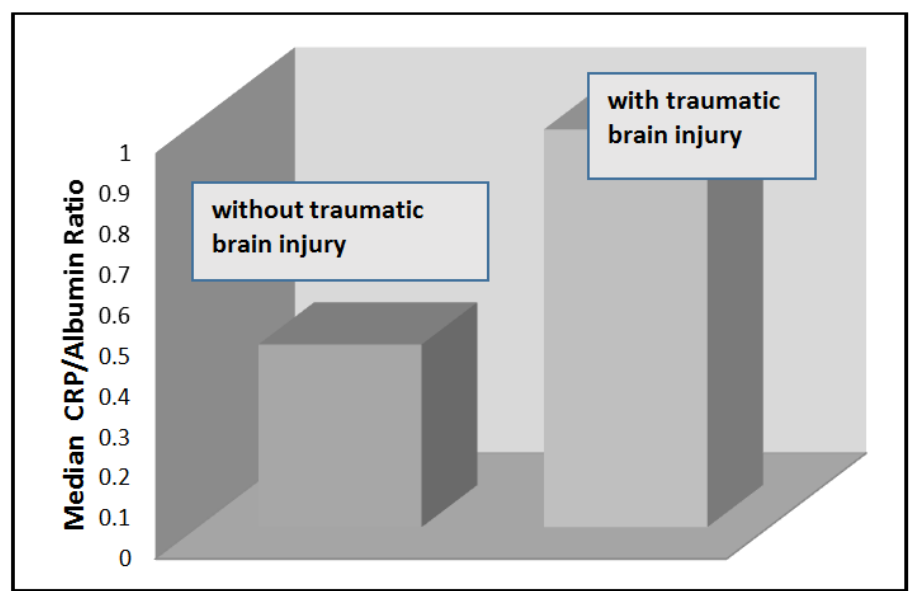

Fig-2: Comparison of the mean serum CRP/albumin levels in patients with traumatic brain injury and without traumatic brain injury 


\begin{tabular}{|l|l|}
\hline Refnum: & \\
\hline Title: & $\begin{array}{l}\text { Predictive Value of the C-Reactive Protein to Albumin Ratio in Patients with Traumatic } \\
\text { Brain Injury }\end{array}$ \\
\hline Date: & $2020 / 01 / 27$ \\
\hline
\end{tabular}

We hereby certify that Textcheck has checked and corrected the English in the manuscript named above.

A specialist editor with suitable professional knowledge (M.Sc. or Ph.D.M.D.) reviewed and corrected the English. An English language specialist subsequently checked the paper again. The first language of both editors is English. $\begin{aligned} & \text { Please direct any questions regarding this certificate or the English in the certified paper to: certified@textcheck.com } \\ & \text { (Please quote our reference number: '20012507') }\end{aligned}$

\section{DISCUSSION}

In patients with TBI, accurate prognostic biomarkers are important for decision-making and management [16]. This is the first in vivo clinical study of the predictive value of the serum CRP/albumin ratio in patients with TBI and its correlation with the severity of head trauma.

Serum albumin is an acute-phase protein the level of which decreases in the presence of inflammation [7]. The CRP/albumin ratio is an inflammation-based prognostic score that has been proposed to be predictive of the clinical outcome and severity of organ dysfunction in various diseases $[8,9]$.

Soltani et al., [7] reported a significant increase in the CRP level and a significant decrease in that of albumin in samples from multiple-trauma patients admitted to an intensive care unit. Al-Subaie et al. detected a strong correlation between hypoalbuminemia and intensive care unit re-admission [8]. In this study, the mean serum CRP/albumin ratio was significantly elevated in head trauma patients, as compared to those without pathological lesions on CCT.

Sung et al., reported significant mortality and morbidity in trauma patients with an albumin level of $<2.6 \mathrm{~g} / \mathrm{dL}$ [17]. In this study, the mean CRP/albumin ratio was significantly increased in patients with TBI. The CRP/albumin ratio was not significantly correlated with the GCS score or the RTS.

Ranzani et al., reported that, as the CRP/albumin ratio increases, the likelihood of discharge from hospital decreased [18]. Likewise, in this study, the mean serum CRP/albumin ratio was higher in hospitalized patients than in those discharged from the ED.

\section{CONCLUSION}

The serum CRP/albumin ratio was increased in patients with TBI and enables discrimination of those with and without pathological lesions demonstrable on CCT. Furthermore, the serum CRP/albumin ratio was not correlated with the severity of head trauma as assessed by the GCS score and the RTS. Consequently, the CRP/albumin ratio might be predictive of traumarelated parenchymal lesions in patients with head trauma.

\section{ACKNOWLEDGEMENTS}

Dr. Serkan Dogan, Emergency Physician, Emergency Medicine department, University of Health Sciences, Kanuni High Speciality Educational and Research Hospital

Dr. Ozgur Sogut, Associate Professor, Emergency Medicine department, University of Health Sciences, Haseki High Speciality Educational and Research Hospital

Dr. Melis Dörter, Assistant, Emergency Medicine department, University of Health Sciences, Kanuni High Speciality Educational and Research Hospital

Dr. Ozgur Deniz Sadioglu, Emergency Physician, Emergency Medicine department, University of Health Sciences, Haseki High Speciality Educational and Research Hospital

Dr. Utku Murat Kalafat, Emergency Physician, Emergency Medicine department, University of Health 
Sciences, Kanuni High Speciality Educational and Research Hospital

Dr. Dilay Satılmıs, Assistant Professor, Emergency Medicine department, University of Health Sciences, Sultan 2. Abdulhamid Han High Speciality Educational and Research Hospital

\section{Funding: None}

Conflict of Interest: None declared.

\section{REFERENCES}

1. Olshaker, J. S., \& Whye, D. W. Jr. (1993). Head trauma. Emerg Med Clin North Am, 11(1):165186.

2. Jennet, B. (1996). Epidemiology of head injury. Journal Neurol Neurosurg Psychiatry, 60(4):362369.

3. Andriessen, T.M., Horn, J., Franschman, G,., van der Naalt, J., Haitsma, I., Jacobs, B., Steyerberg, E. W., \& Vos, P. E. (2011). Epidemiology, severity classification, and outcome of moderate and severe traumatic brain injury: a prospective multicenter study. Journal Neurotrauma, 28(10):2019-2031.

4. Chen, J. H., Xu, Y. N., Ji, M., Li, P. P., Yang, L. K., \& Wang, Y. H. (2018). Multimodal monitoring combined with hypothermia for the management of severe traumatic brain injury: A case report. Exp Ther Med, 15(5):4253-4258.

5. Taylor, C. A., Bell, J. M., Breiding, M. J., \& Xu, L. (2017). Traumatic Brain Injury-Related Emergency Department Visits, Hospitalizations, and Deaths - United States, 2007 and 2013. MMWR Surveill Summ, 66(9):1-16.

6. Devran, O., Karakurt, Z., Adıgüzel, N., Güngör, G., Moçin, O.Y., Balcı, M. K., Celik, E., Saltürk, C., Takır, H. B., Kargın, F., \& Yılmaz, A. (2012). $\mathrm{C}$-reactive protein as a predictor of mortality in patients affected with severe sepsis in intensive care unit. Multidiscip Respir Med, 7(1):47.

7. Soltani, F., Pipelzadeh, M., Akhondzadeh, R., Rashidi, M., \& Ekrami, A. (2015). Evaluation of C - reactive Protein, Albumin and the C - reactive Protein/Albumin Ratio as Prognostic Markers in Trauma Patients Admitted to Intensive Care Unit. Journal of Advances in Medicine and Medical Research, 12(10), 1-7.

8. Al-Subaie, N., Reynolds, T., Sunderland, R., Myers, A., Morgan, P., Grounds, R. M., \& Rhodes, A. (2008). Plasma C-reactive protein and albumin as predictors of readmission to intensive care. Critical Care, 12(2), P174.

9. Kinoshita, A., Onoda, H., Imai, N., Iwaku, A., Oishi, M., Tanaka, K., Fushiya, N., Koike, K.,
Nishino, H., \& Matsushima, M. (2015). The Creactive protein/albumin ratio, a novel inflammation-based prognostic score, predicts outcomes in patients with hepatocellular carcinoma. Ann Surg Oncol, 22(3):803-810.

10. Gibson, D. J., Hartery, K., Doherty, J., Nolan, J., Keegan, D., Byrne, K., Martin, ST., Buckley, M, Sheridan, J., Horgan, G., Mulcahy, H. E., Cullen, G., \& Doherty, G. A. (2018). CRP/Albumin Ratio: An Early Predictor of Steroid Responsiveness in Acute Severe Ulcerative Colitis. J Clin Gastroenterol, 52(6):e48-e52.

11. Huang, S. S., Xie, D. M., Cai, Y. J., Wu, J. M., Chen, R. C., Wang, X. D., Song, M., Zheng, M. H., Wang, Y. Q., Lin, Z., \& Shi K. Q. (2017). Creactive protein-to-albumin ratio is a predictor of hepatitis B virus related decompensated cirrhosis: time-dependent receiver operating characteristics and decision curve analysis. Eur J Gastroenterol Hepatol, 29(4):472-480.

12. Kaplan, M., Ates, I., Akpinar, M. Y., Yuksel, M., Kuzu, U. B., Kacar, S., Coskun, O., \& Kayacetin, E. (2017). Predictive value of C-reactive protein/albumin ratio in acute pancreatitis. Hepatobiliary Pancreat Dis Int, 16(4):424-430.

13. Lelubre, C., Anselin, S., Zouaoui Boudjeltia, K., Biston, P., \& Piagnerelli, M. (2013). Interpretation of C-reactive protein concentrations in critically ill patients. Biomed Res Int, 2013:124021.

14. Wada, H., Dohi, T., Miyauchi, K., Doi, S., Naito, R., Konishi, H., Tsuboi, S., Ogita, M., Kasai, T., Okazaki, S., Isoda, K., Suwa, S., \& Daida, H. (2017). Independent and Combined Effects of Serum Albumin and C-Reactive Protein on LongTerm Outcomes of Patients Undergoing Percutaneous Coronary Intervention. Circ J, 81(9):1293-1300.

15. Papa, L., Stiell, I. G., Clement, C. M., Pawlowicz, A., Wolfram, A., Braga, C., Draviam, S., \& Wells, G. A. (2012). Performance of the Canadian CT Head Rule and the New Orleans Criteria for predicting any traumatic intracranial injury on computed tomography in a United States Level I trauma center. Acad Emerg Med, 19(1):2-10.

16. Feng, J., \& Jiang, J. (2020). Traumatic brain injury in 2019: databases, biomarkers, and stratified treatment. Lancet Neurol, 19(1):5-7.

17. Sung, J., Bochicchio, G. V., Joshi, M., Bochicchio, K., Costas, A., Tracy, K., \& Scalea, T. M. (2004). Admission serum albumin is predicitve of outcome in critically ill trauma patients. Am Surg, 70(12):1099-1102.

18. Ranzani, O. T., Zampieri, F. G., Forte, D. N., Azevedo, L. C., \& Park, M. (2013). C-reactive protein/albumin ratio predicts 90 -day mortality of septic patients. PLoS One, 8(3):e59321. 